\title{
Associação de marcadores microssatélites com teores de óleo e proteína em soja
}

\author{
Josiane Isabela da Silva Rodrigues(1), Klever Márcio Antunes Arruda(1), Cosme Damião Cruz ${ }^{(1)}$, \\ Newton Deniz Piovesan ${ }^{(1)}$, Everaldo Gonçalves de Barros $^{(1)}$ e Maurilio Alves Moreira ${ }^{(1)}$
} (1)Universidade Federal de Viçosa, Instituto de Biotecnologia Aplicada à Agropecuária, Avenida PH Rolfs s/no, CEP 36570000 Viçosa, MG.
E-mail: josianeisabela@gmail.com, kleverantunes@yahoo.com.br, cdcruz@ufv.br, piovesan@ufv.br, ebarros@ufv.br, moreira@ufv.br

Resumo - O objetivo deste trabalho foi avaliar a associação de marcadores microssatélites localizados próximos a locos de caracteres quantitativos (QTL) descritos na literatura, com os teores de óleo e proteína de genótipos de soja cultivados no Brasil. Quarenta e nove genótipos de soja foram avaliados em Viçosa, MG (12/2009); Visconde do Rio Branco, MG (2/2010); e São Gotardo, MG (2/2010 e 10/2011). Utilizou-se o delineamento de blocos ao acaso, com três repetições. Os teores de óleo e proteína foram determinados por espectrometria do infravermelho. Foi observada ampla variabilidade genética para esses teores. Dos 65 marcadores microssatélites testados, 35 apresentaram associação significativa com pelo menos um dos teores, mas poucos foram consistentes com a mudança de ambiente. Ao se levar em conta a consistência da associação em todos os ambientes, os marcadores Satt239, Satt384 e Satt562 destacam-se para a seleção assistida quanto aos teores de óleo e de proteína, enquanto o Satt310 destaca-se para seleção quanto ao teor de óleo, e o Satt567, quanto ao de proteína.

Termos para indexação: Glycine max, melhoramento, QTL, seleção assistida.

\section{Association of microsatellite markers with contents of oil and protein in soybean}

\begin{abstract}
The objective of this work was to evaluate the association of microsatellite markers located close to quantitative trait loci (QTL) described in the literature, with contents of oil and protein soybean genotypes cultivated in Brazil. Forty-nine soybean genotypes were evaluated in Viçosa, MG (12/2009), Visconde do Rio Branco, MG (2/2010), and São Gotardo, MG (2/2010 and 10/2011). A randomized complete block design, with three replicates, was used. The oil and protein contents were determined by infrared spectroscopy. A high genetic variability was observed for oil and protein contents. Among the 65 tested microsatellite markers, 35 showed significant association with at least one of these contents, but few of them were consistent with the change of environment. Considering the consistency of the association in all environments, the markers Satt239, Satt384, and Satt562 stand out for assisted selection as to oil and protein contents, whereas Satt310 stands out for the selection as to oil content, and Satt567, as to protein content.
\end{abstract}

Index terms: Glycine max, breeding, QTL, assisted selection.

\section{Introdução}

Por se tratarem de caracteres quantitativos, os teores de óleo e proteína têm controle genético complexo.Além disso, há relatos da existência de interações genótipo $\mathrm{x}$ ambiente para estas características (Marquez, 2010). Assim, a variedade de locos envolvidos na expressão fenotípica e a influência ambiental sobre os caracteres são fatores que dificultam o melhoramento.

Em soja, há correlação negativa entre os teores de óleo e proteína e, frequentemente, entre o teor de proteína e a produtividade. Por sua vez, a relação entre o teor de óleo e a produtividade é positiva, o que torna possível manter a produtividade quando se pratica a seleção para alto teor de óleo. No entanto, o aumento no potencial produtivo ou no teor de óleo pode causar redução no teor de proteína, o que também traz dificuldades ao melhoramento (Finoto, 2008).

Frente a estas dificuldades, a obtenção de maiores teores de óleo e de proteína pode ser facilitada pela seleção com o auxílio de marcadores moleculares. Vários marcadores de locos de caracteres quantitativos (QTL) foram relatados para teores de óleo e proteína em soja (Sebolt et al., 2000; Csanádi et al., 2001; Specht et al., 2001; Chung et al., 2003; Chapman et al., 2003; Tajuddin et al., 2003; Fasoula et al., 2004; Hyten et al., 2004; Zhang et al., 2004; Panthee et al., 
2005; Nichols et al., 2006; Reinprecht et al., 2006; Chen et al., 2007), mas poucos foram confirmados.

Em cultivares brasileiras, quatro QTL associados ao teor de proteína foram mapeados por Rodrigues et al. (2010), nos grupos de ligação D1a, G, A1 e I, além de outros três QTL para o teor de óleo, nos grupos A1, I e O, que explicaram de 6,24 a $18,94 \%$ da variação nos teores de proteína, e de 17,26 a 25,93\%, nos de óleo. Outros cinco QTL, nos grupos de ligação C2, D1a, E, $\mathrm{Ne} \mathrm{G}$, associados ao teor de proteína, foram mapeados em condições tropicais por Soares et al. (2008) e explicaram entre 7,34 e $14,37 \%$ da variação no teor de proteína. Na mesma região do grupo de ligação $\mathrm{E}$, foi mapeado um QTL que explicou 7,51\% da variação no teor de proteína (Piovesan, 2008).

Há relatos de QTL que explicam percentuais de variação muito elevados, embora poucos tenham sido confirmados. Nos trabalhos de Diers et al. (1992) e Sebolt et al. (2000), os QTL para proteína mapeados chegaram a explicar $65 \%$ da variação fenotípica. É possível que estes valores tenham sido superestimados em razão do uso de populações reduzidas. Diers et al. (1992) e Lee et al. (1996), também com número reduzido de progênies - de 60 a 120, respectivamente - mapearam QTL que explicaram até $43 \%$ da variação no teor de proteína.

Apesar do grande número de QTL relatados na literatura, relacionados aos teores de óleo e proteína, muitos foram mapeados em PIs (acessos) ou em cultivares com genealogia distinta do germoplasma de soja cultivado no Brasil. Dessa forma, para que haja maior eficiência, a seleção assistida com base nestas regiões deve ser precedida pela confirmação dos efeitos de cada QTL.

O objetivo deste trabalho foi avaliar a associação de marcadores microssatélites localizados próximos a QTL descritos na literatura com os teores de óleo e proteína de genótipos de soja cultivados no Brasil.

\section{Material e Métodos}

Foram genotipados dois grupos de variedades e linhagens de soja (Glycine max L.) com marcadores microssatélites localizados próximos a QTL para os teores de óleo e proteína. Esses genótipos foram avaliados fenotipicamente em diferentes ambientes. Os grupos apresentavam variação quanto aos teores de óleo (grupo I) e de proteína (grupo II). O grupo I foi formado pelos genótipos BRSMG Garantia, FMT Tucunaré, BRSGO Luziânia, MG/BR 46 Conquista, Suprema, BARC8, CS 303 TNKCA, Vencedora, PI 181544, PI 371611, PI 371610, CD 225RR, CD 224, CD 219RR, PI 235347, CD 226RR, UFV20, CD 222, CD 01RR8376, CD 983321RR, BR 8014887 e CD 01RR8384. O grupo II pelos genótipos BRSMG Garantia, FMT Tucunaré, BRSGO Luziânia, UFV16, CS 3032PTA182, BRS Sambaíba, CS 94731, MSOY 8914, UFV18, MSOY 8400, DM339, UFVS 2012, UFVS 2011, MSOY 8001, UFVS 2001, MG/BR 46 Conquista, Suprema, MSOY 6101, PI 417360, CS 3032PTA19051, CS 3032PTA137410, B3 PTA382210, CS 3032PTA27634, B3 PTA21619, BARC8, CS 3032PTA27612, CS 3032PTA16712, B3 PTA21334 e BR 8014887. No grupo I, as amostras de DNA dos genótipos foram amplificadas com 33 marcadores microssatélites, localizados próximos a QTL para o teor de óleo. Já no grupo II, as amostras de DNA foram amplificadas com 39 marcadores microssatélites, próximos a QTL para o teor de proteína.

Os marcadores utilizados para seleção quanto ao teor de óleo foram relatados por Csanádi et al. (2001), Specht et al. (2001), Chung et al. (2003), Tajuddin et al. (2003), Fasoula et al. (2004), Hyten et al. (2004), Panthee et al. (2005), Reinprecht et al. (2006), Chen et al. (2007), Li et al. (2007), Shibata et al. (2008) e Rodrigues et al. (2010). Os utilizados para seleção quanto à proteína foram relatados por Orf et al. (1999), Sebolt et al. (2000), Csanádi et al. (2001), Specht et al. (2001), Chapman et al. (2003), Chung et al. (2003), Tajuddin et al. (2003), Hyten et al. (2004), Reinprecht et al. (2006), Chen et al. (2007) e Soares et al. (2008).

A extração de DNA foi realizada com uso do kit de extração de DNA genômico Wizard Plus SV Miniprep DNA Purification System (Promega, Madison, WI, EUA). As reações de amplificação tiveram volume final de $15 \mu \mathrm{L}$ e as seguintes condições: TrisHCl $10 \mathrm{mmol} \mathrm{L}^{-1}$, pH 8,3; $\mathrm{KCl} 50 \mathrm{mmol} \mathrm{L}^{-1}$; $\mathrm{MgCl}_{2} 2 \mathrm{mmol} \mathrm{L}^{-1}$; Triton X100 0,1\%; $100 \mu \mathrm{mol} \mathrm{L}^{-1}$ de cada um dos desoxinucleotídios; $0,3 \mu \mathrm{mol} \mathrm{L}^{-1}$ de cada iniciador (Research Genetics Inc., Huntsville, AL, EUA); uma unidade de Taq polimerase; e $30 \mathrm{ng}$ de DNA. As reações de PCR consistiram de passo inicial de $94^{\circ} \mathrm{C}$ por $4 \mathrm{~min} ; 30$ ciclos de $94^{\circ} \mathrm{C}$ por $1 \mathrm{~min}, 55^{\circ} \mathrm{C}$ por $1 \mathrm{~min}$ e $72^{\circ} \mathrm{C}$ por $2 \mathrm{~min}$; e uma etapa final de $72^{\circ} \mathrm{C}$ por $7 \mathrm{~min}$. Os produtos de amplificação 
foram separados por eletroforese em géis verticais de poliacrilamida $10 \%$, com uso de tampão TAE $1 \mathrm{X}$ (Trisacetato $40 \mathrm{mmol} \mathrm{L}^{-1}$ e EDTA $1 \mathrm{mmol} \mathrm{L}^{-1}$ ) e período de corrida de 3 horas, a 140 volts. Após a eletroforese, os géis foram corados com nitrato de prata $2 \%$ e fotografados com equipamento de captura de imagem, modelo LPIX EX (Loccus Biotecnologia, Cotia, São Paulo).

Para a avaliação fenotípica, os genótipos foram cultivados em: Viçosa, MG (12/2009); Visconde do Rio Branco, MG (2/2010); e São Gotardo, MG (2/2010 e 10/2011). Utilizou-se o delineamento de blocos ao acaso com três repetições. As parcelas consistiram de fileiras de $1 \mathrm{~m}$, semeadas com 15 sementes. O espaçamento entre as parcelas foi de 0,5 m. Após a colheita manual, os grãos foram triturados em moinho industrial, modelo MA020 (Marconi Equipamentos para Laboratórios Ltda., Piracicaba, SP). O farelo de soja foi analisado por espectrometria do infravermelho, com espectrômetro FTNIR, modelo Antaris II (Thermo Fisher Scientific Brasil Instrumentos de Processo Ltda., São Paulo, SP).

A análise de variância dos dados fenotípicos foi realizada com base no modelo fatorial: $\mathrm{Y}_{\mathrm{ijk}}=\mu+\mathrm{G}_{\mathrm{i}}+\mathrm{A}_{\mathrm{j}}+\mathrm{GA}_{\mathrm{ij}}+\mathrm{B} / \mathrm{A}_{\mathrm{jk}}+\varepsilon_{\mathrm{ijk}}$, em que $\mathrm{G}$ representa o efeito fixo e $\mathrm{A}$, o aleatório.

A associação entre marcadores e valores fenotípicos nos grupos foi avaliada por análise de variância individual, em cada ambiente, e pelos valores de média fenotípica dos quatro ambientes, para cada característica e loco particular. Utilizou-se a estatística F para avaliar se houve diferença entre as classes genotípicas observadas em cada loco marcador, e o teste t para analisar a significância dos contrastes entre as médias genotípicas. Foram utilizados os programas Genes (Cruz, 2006) e GQMOL (Cruz \& Schuster, 2004).

\section{Resultados e Discussão}

De acordo com a análise de variância conjunta dos valores fenotípicos, a variabilidade genética foi significativa $(\mathrm{p}<0,01)$ para os teores de óleo e proteína, nos dois grupos (Tabela 1). No grupo I, os percentuais de óleo variaram de 17,28 a $23,01 \%$ e os de proteína, de 34,25 a $45,18 \%$. No grupo II, estes percentuais variaram de 16,48 a $23,01 \%$ e de 34,25 a $45,18 \%$, respectivamente.
No grupo I, foram observadas 21 associações significativas para teor de proteína e 21 para teor de óleo. Para a média geral nos quatro ambientes, seis associações significativas foram observadas para os teores de óleo e de proteína. Neste grupo, 15 marcadores microssatélites não foram significativos. No grupo II, foram observadas 41 associações significativas para teor de óleo e 38 para teor de proteína. Quanto à média geral nos quatro ambientes, oito associações foram observadas para ambos os teores. Neste grupo, 20 marcadores não tiveram associação com os teores de óleo ou proteína. Dos 65 marcadores moleculares testados, 35 tiveram associação significativa pelo teste $\mathrm{F}$ com pelo menos um teor; porém, poucos foram consistentes com a variação de ambiente (Tabela 2).

Dos oito marcadores microssatélites do grupo de ligação I (GL I) - principal grupo no controle genético dos teores de óleo e proteína em soja descrito na literatura - seis (Satt496, Satt562, Satt239, Satt270, Satt367 e Satt419) tiveram associação significativa com pelo menos um dos teores. Os marcadores Satt239, Satt384 e Satt562 tiveram associação significativa $(\mathrm{p}<0,01)$ tanto com o teor de óleo quanto com o de proteína, em todos os ambientes, e também com a média das variáveis nos quatro ambientes. Esses QTL de efeito maior para teores de óleo e proteína foram mapeados no GL I por Brummer et al. (1997), Sebolt et al. (2000), Chung et al. (2003), Tajuddin et al. (2003) e Nichols et al. (2006), com uso de populações de mapeamento originadas de diferentes "backgrounds" genéticos.

Tabela 1. Resumo da análise de variância dos teores de óleo e proteína de 49 genótipos de soja, cultivados em Viçosa, MG (12/2009), Visconde do Rio Branco, MG (2/2010) e São Gotardo, MG (2/2010 e 10/2011).

\begin{tabular}{lccc}
\hline Fator de variação & GL & \multicolumn{2}{c}{ Quadrados médios } \\
\cline { 3 - 4 } & & Teor de proteína & Teor de óleo \\
\hline Bloco/ambiente & 8 & 11,73 & 8,31 \\
Genótipo (G) & 48 & $89,22^{* *}$ & $30,39^{* *}$ \\
Ambiente (A) & 3 & $236,44^{* *}$ & $63,53^{* *}$ \\
G x A & 144 & $6,56 * *$ & $3,80^{* *}$ \\
Resíduo & 384 & 2,00 & 0,82 \\
\hline Média geral (\%) & & 39,67 & 19,51 \\
CV (\%) & & 3,56 & 4,64 \\
Maior QMR/menor QMR & & 3,77 & 3,50 \\
CVg/CVe & & 1,86 & 1,64 \\
\hline
\end{tabular}

**Significativo pelo teste $\mathrm{F}$, a $1 \%$ de probabilidade. QMR, quadrado médio do resíduo; $\mathrm{CVg}$, coeficiente de variação genético; $\mathrm{CVe}$, coeficiente de variação experimental.

Pesq. agropec. bras., Brasília, v.48, n.3, p.255-262, mar. 2013 DOI: $10.1590 / \mathrm{S} 0100-204 X 2013000300003$ 
Sete marcadores microssatélites no grupo I e nove no grupo II (Tabela 2) tiveram associação simultânea com os teores de óleo e proteína. Este tipo de associação foi comum para a maioria dos QTL mapeados por Zhang et al. (2004), que detectaram QTL que influenciam, ao mesmo tempo, até cinco características agronômicas distintas. Esse efeito pleiotrópico explica a correlação genética negativa existente entre os teores de óleo e proteína em soja (Fasoula et al., 2004).

Quanto ao teor de óleo dos genótipos avaliados pelo teste $\mathrm{t}$, houve pelo menos um contraste significativo entre as médias, para 23 marcadores (Tabela 3). Em relação ao teor de proteína, este número foi de 20 marcadores (Tabela 4). Destes, 13 foram associados simultaneamente aos teores de proteína e óleo. De modo similar, Shi et al. (2010), ao trabalhar com 105 genótipos de soja oriundos da Ásia e dos Estados Unidos, avaliados com 65 marcadores microssatélites, encontraram 13 marcadores associados com teor de óleo, distribuídos em 11 grupos de ligação, e 19 relacionados com teor de proteína, distribuídos em 14 grupos de ligação. Destes, 12 foram associados simultaneamente ao teor de proteína e de óleo.

Os marcadores microssatélites significativos, encontrados no presente trabalho, confirmam QTL anteriormente mapeados em 11 grupos de ligação de soja e poderão ser eficazes para a seleção de combinações alélicas favoráveis para maiores percentuais de óleo e proteína.

Tabela 2. Associação de marcadores microssatélites com os teores de óleo e proteína, nos grupos I e II de genótipos de soja, por análise de variância em diferentes ambientes.

\begin{tabular}{|c|c|c|c|c|c|c|c|c|c|c|c|c|c|c|}
\hline \multirow{2}{*}{$\begin{array}{l}\text { Marcador } \\
\text { molecular }\end{array}$} & \multirow{2}{*}{ Grupo } & \multicolumn{5}{|c|}{ Teor de proteína $(\%)$} & \multicolumn{5}{|c|}{ Teor de óleo (\%) } & \multirow[t]{2}{*}{$\mathrm{P}$} & \multirow[t]{2}{*}{ OL } & \multirow[t]{2}{*}{$\mathrm{P} / \mathrm{OL}$} \\
\hline & & A1 & $\mathrm{A} 2$ & A3 & A4 & A1-4 & $\mathrm{A} 1$ & $\mathrm{~A} 2$ & A3 & A4 & A1-4 & & & \\
\hline Satt006 & I & ns & ns & $\begin{array}{ll}\mathrm{ns} \\
\mathrm{ns}\end{array}$ & ns & ns & $* *$ & $\mathrm{~ns}$ & $\mathrm{~ns}$ & ns & $*$ & $\begin{array}{l}\mathrm{ns} \\
\mathrm{ns}\end{array}$ & $*, * *$ & ns \\
\hline Satt020 & I & ns & * & $*$ & * & * & ns & ns & ns & ns & ${ }_{-\mathrm{ns}}$ & $*$ & ns & ns \\
\hline Satt114 & I & ns & ns & ns & ns & ns & * & ns & ns & * & ns & ns & * & * \\
\hline Satt141 & I & ns & * & ns & ns & ns & ns & * & ns & ns & ns & $*$ & $*$ & $*$ \\
\hline Satt147 & II & $*$ & ns & ns & ns & & ns & $*$ & ns & ns & ns & $*$ & $*$ & $*$ \\
\hline Satt156 & I & $* *$ & ns & $* *$ & $*$ & $* *$ & ns & ns & $* *$ & ns & * & $*, * *$ & $*, * *$ & $*, * *$ \\
\hline Satt166 & I & $*$ & ns & ns & ns & ns & * & ns & ns & ns & ns & $*$ & $*$ & $*$ \\
\hline Satt196 & I e II & ns & ns & ns & ns & ns & ns & * & ns & ns & ns & ns & * & ns \\
\hline Satt200 & I & $*$ & ns & ns & ns & ns & $\mathrm{ns}$ & ns & ns & ns & ns & * & ns & ns \\
\hline Satt229 & I & $* *$ & ns & ns & $*$ & $*$ & $* *$ & ns & ns & ns & $*$ & $*, * *$ & $*, * *$ & $*, * *$ \\
\hline Satt239 & II & $* *$ & $* *$ & $* *$ & $* *$ & $* *$ & $* *$ & $* *$ & $* *$ & $* *$ & $* *$ & $* *$ & $* *$ & $* *$ \\
\hline Satt259 & I & ns & ns & ns & ns & ns & $* *$ & ns & ns & ns & ns & ns & $* *$ & ns \\
\hline Satt270 & II & * & ns & $* *$ & $* *$ & $* *$ & ns & ns & $* *$ & ns & * & $*, * *$ & $*, * *$ & $*, * *$ \\
\hline Satt281 & II & ns & $*$ & ns & ns & ns & ns & ns & ns & ns & ns & $*$ & ns & ns \\
\hline Satt286 & II & ns & $*$ & $\% *$ & ns & ns & ns & $* *$ & $*$ & ns & ns & $*, * *$ & $*, * *$ & $*, * *$ \\
\hline Satt301 & II & ns & ns & ns & ns & ns & ns & $* *$ & ns & * & ns & ns & $* * * *$ & ns \\
\hline Satt308 & I & * & $* *$ & ns & ns & ns & $* *$ & $* *$ & $* *$ & ns & $* *$ & $*, * *$ & $* *$ & $* * * *$ \\
\hline Satt310 & II & $*$ & ns & $*$ & $* *$ & $*$ & $* *$ & $*$ & $*$ & $* *$ & $* *$ & $*, * *$ & $*, * *$ & $*, * *$ \\
\hline Satt335 & II & $*$ & ns & ns & ns & ns & $*$ & ns & ns & $*$ & ns & $*$ & $*$ & * \\
\hline Satt355 & I & ns & ns & $*$ & ns & $*$ & ns & ns & ns & ns & ns & $*$ & ns & ns \\
\hline \multirow{2}{*}{ Satt384 } & I & ns & ns & ns & $*$ & ns & ns & ns & ns & $*$ & ns & $*$ & $*$ & $*$ \\
\hline & II & $* *$ & $* *$ & $\% *$ & $* *$ & $* *$ & $*$ & $* *$ & $* *$ & $* *$ & $* *$ & $* *$ & $*, * *$ & $* * * *$ \\
\hline Satt367 & II & ns & ns & ns & ns & ns & ns & ns & ns & ns & * & ns & $*$ & ns \\
\hline Satt373 & II & ns & $* *$ & $*$ & * & $*$ & ns & $* *$ & * & $* *$ & * & $*, * *$ & $* *$ & $*, * *$ \\
\hline Satt398 & I & ns & ns & $* *$ & $*$ & $*$ & ns & ns & * & $* *$ & * & $*, * *$ & $*, * *$ & $*, * *$ \\
\hline Satt408 & II & ns & ns & ns & ns & ns & $* *$ & ns & ns & ns & ns & $\mathrm{ns}$ & $* *$ & $\mathrm{~ns}$ \\
\hline Satt419 & II & ns & ns & ns & ns & ns & $*$ & $* *$ & ns & ns & ns & ns & $*, * *$ & ns \\
\hline Satt469 & II & ns & ns & ns & ns & ns & ns & $* *$ & ns & ns & ns & ns & $* *$ & ns \\
\hline Satt476 & II & $*$ & ns & $* *$ & ns & $*$ & ns & ns & ns & ns & ns & $*, * *$ & ns & ns \\
\hline Satt486 & II & * & ns & ns & $*$ & $*$ & ns & ns & ns & ns & ns & $*$ & ns & ns \\
\hline Satt496 & II & ns & ns & ns & * & ns & ns & ns & ns & ns & ns & $*$ & ns & ns \\
\hline Satt510 & I & ns & ns & ns & ns & ns & ns & ns & ns & $*$ & ns & ns & * & ns \\
\hline Satt551 & I & ns & ns & ns & ns & ns & ns & $* *$ & ns & ns & ns & ns & $* *$ & ns \\
\hline Satt562 & I & $* *$ & $* *$ & * & * & $*$ & * & $* *$ & $* *$ & $*$ & $* *$ & $*, * *$ & $*, * *$ & $*, * *$ \\
\hline Satt567 & II & $* *$ & $* *$ & * & $* *$ & $* *$ & ns & $* *$ & ns & $* *$ & $*$ & $*, * *$ & $* ; * *$ & $*, * *$ \\
\hline Satt570 & II & ns & ns & ns & ns & ns & $*$ & $\mathrm{~ns}$ & $* *$ & $*$ & $* *$ & $\mathrm{~ns}$ & $*, * *$ & $\mathrm{~ns}$ \\
\hline
\end{tabular}

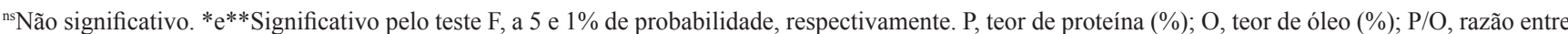
teores de proteína e óleo. A1 a A4, médias fenotípicas nos experimentos de Viçosa (12/2009), Visconde do Rio Branco (2/2010), São Gotardo (2/2010) e São Gotardo (10/2011); A1-4, médias fenotípicas nos quatro ambientes. 
Tabela 3. Médias das classes genotípicas em locos microssatélites e contraste entre médias quanto ao teor de óleo nos grupos I e II de genótipos de soja.

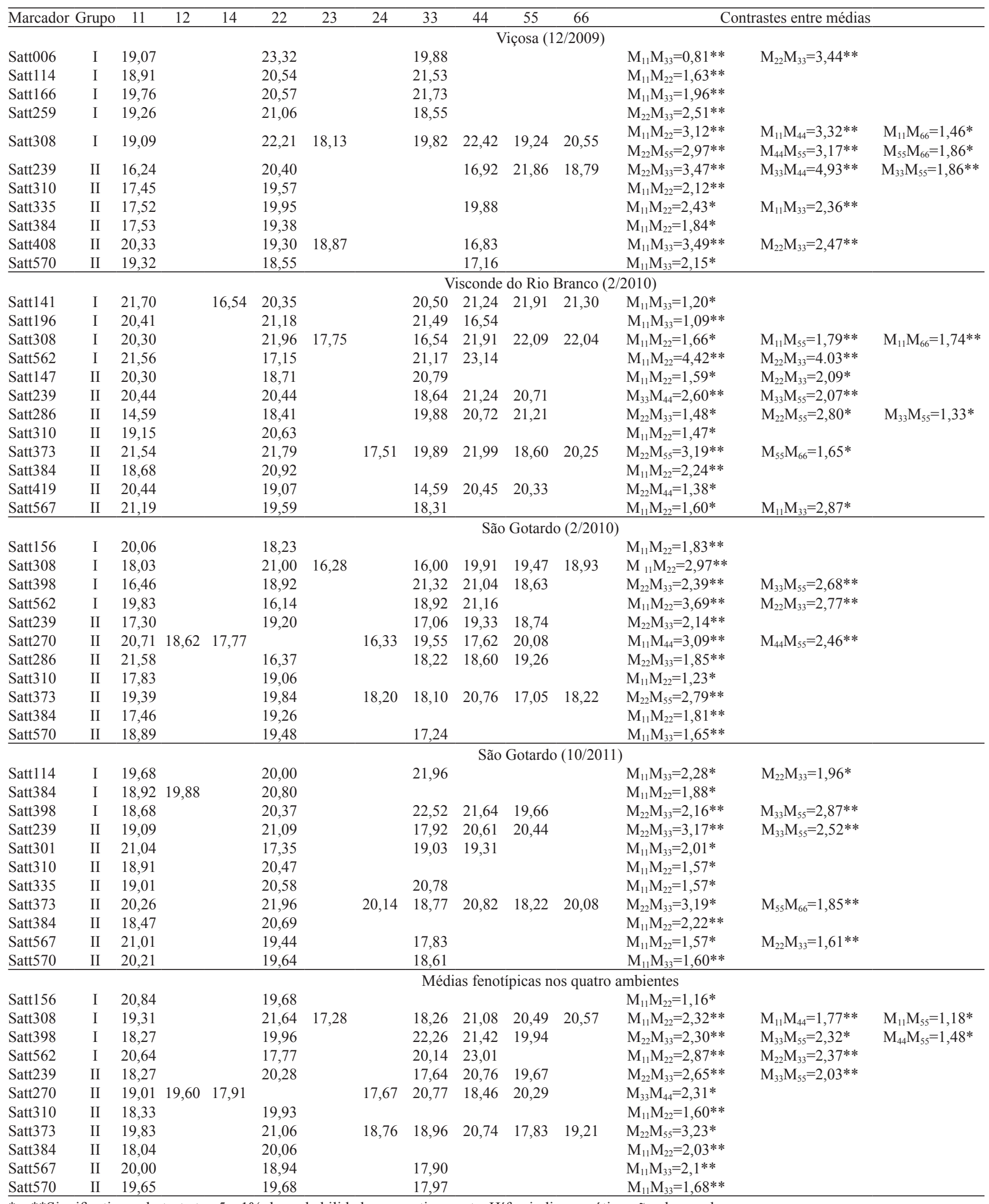

* e **Significativo pelo teste t, a 5 e $1 \%$ de probabilidade, respectivamente. Hífen indica genótipo não observado. 
Tabela 4. Médias das classes genotípicas em locos microssatélites e contraste entre médias quanto ao teor de proteína nos grupos I e II de genótipos de soja.

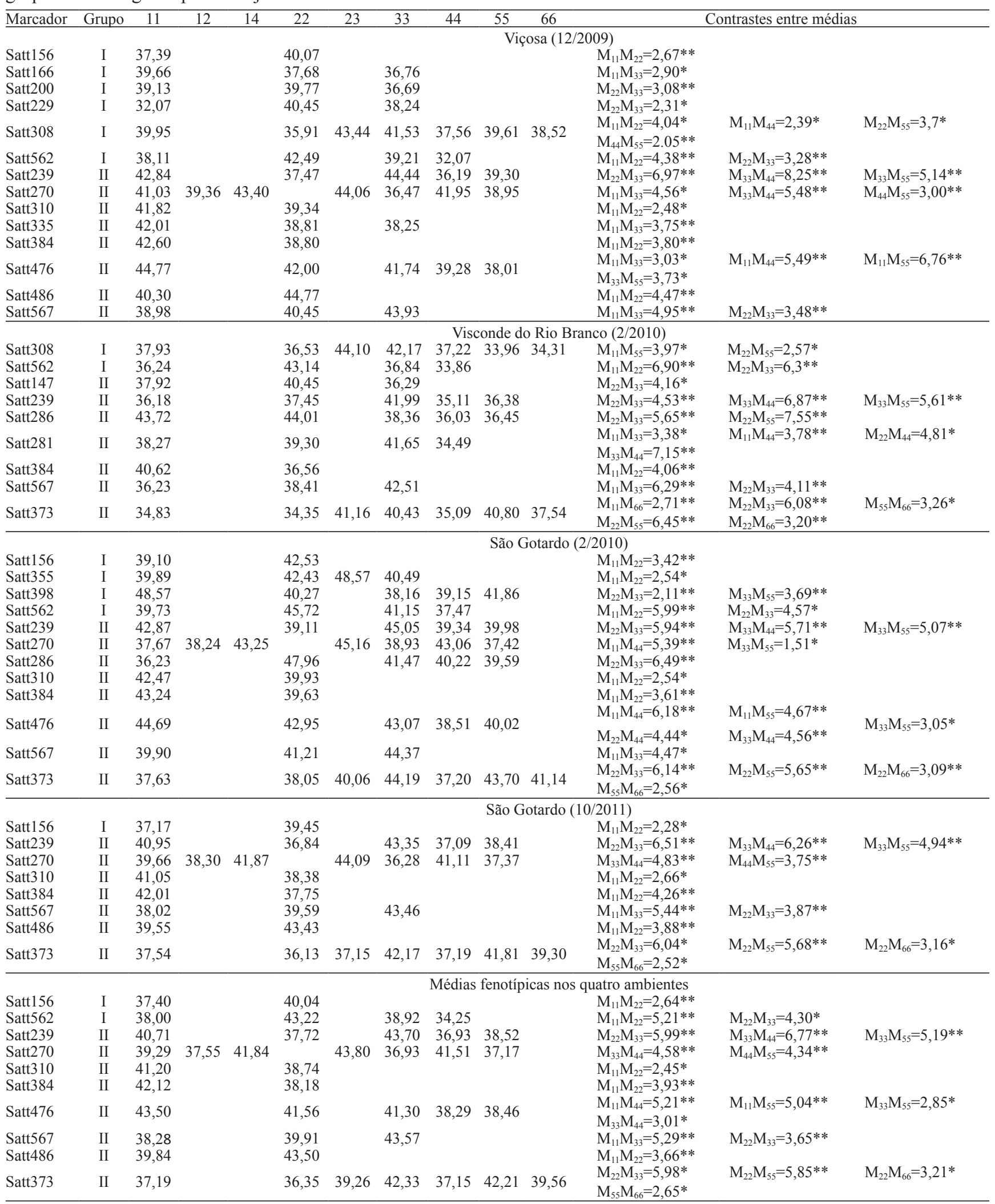

* e**Significativo pelo teste t, a 5 e $1 \%$ de probabilidade, respectivamente. Hífen indica genótipo não observado. 


\section{Conclusões}

1. Trinta e cinco marcadores microssatélites estiveram associados com os teores de óleo e proteína, mas essa associação não foi consistente na avaliação em todos os ambientes.

2. Ao se levar em conta a consistência da associação em todos os ambientes, os marcadores microssatélites Satt239, Satt384 e Satt562 destacam-se para a seleção assistida quanto aos teores de óleo e de proteína, enquanto o Satt310 destaca-se para seleção quanto ao teor de óleo, e o Satt567, quanto ao de proteína.

\section{Agradecimentos}

Ao Conselho Nacional de Desenvolvimento Científico e Tecnológico (CNPq) e à Fundação de Amparo à Pesquisa do Estado de Minas (Fapemig), pelo apoio financeiro.

\section{Referências}

BRUMMER, E.C.; GREAF, G.L.; ORF, J.; WILCOX J.R.; SHOEMAKER, R.C. Mapping QTL for seed protein and oil content in eight soybean populations. Crop Science, v.37, p.370378, 1997. DOI: 10.2135/cropsci1997.0011183X003700020011x.

CHAPMAN, A.; PANTALONE, V.R.; USTUN, A.; ALLEN, F.L.; LANDAUELLIS, D.; TRIGIANO, R.N.; GRESSHOFF, P.M. Quantitative trait loci for agronomic and seed quality traits in an $F_{2}$ and $F_{4: 6}$ soybean population. Euphytica, v.129, p.387-393, 2003. DOI: $10.1023 / \mathrm{A}: 1022282726117$.

CHEN, Q.S.; ZHANG, Z.C.; LIU, C.Y.; XIN, D.W.; QIU, H.M.; SHAN, D.P.; SHAN, D.P.; HU, G.H. QTL analysis of major agronomic traits in soybean. Agricultural Sciences in China, v.6, p.399-405, 2007. DOI: 10.1016/S16712927(07)600625.

CHUNG, J.; BABKA, H.L.; GRAEF, G.L.; STASWICK, P.E.; LEE, D.J.; CREGAN, P.B.; SHOEMAKER, R.C.; SPEECH, J.E. The seed protein, oil, and yield QTL on soybean linkage group I. Crop Science, v.43, p.1053-1067, 2003. DOI: 10.2135/ cropsci2003.1053.

CRUZ, C.D. Programa Genes: biometria. Viçosa: UFV, 2006. $382 \mathrm{p}$.

CRUZ, C.D.; SCHUSTER, I. GQMOL: aplicativo computacional para análise de dados moleculares e de suas associações com caracteres quantitativos. Versão 2.1. Viçosa: UFV, 2004. Disponível em: <www.ufv.br/dbg/gqmol/gqmol.htm>. Acesso em: 2 fev. 2012.

CSANÁDI, G.; VOLLMANN, J.; STIFT, G.; LELLEY, T. Seed quality QTL identified in a molecular map of early maturing soybean. Theoretical and Applied Genetics, v.103, p.912-919, 2001. DOI: $10.1007 / \mathrm{s} 001220100621$.

DIERS, B.W.; KEIM, P.; FEHR, W.R.; SHOEMAKER, R.C. RFLP analysis of soybean seed protein and oil content. Theoretical and Applied Genetics, v.83, p.608-612, 1992. DOI: 10.1007/ BF00226905.

FASOULA, V.A.; HARRIS, D.K.; BOERMA, H.R. Validation and designation of quantitative trait loci for seed protein, seed oil, and seed weight from two soybean populations. Crop Science, v.44, p.1218-1225, 2004. DOI: 10.2135/cropsci2004.1218.

FINOTO, E.L. Variabilidade fenotípica dos teores de óleo e proteína de cultivares de soja em diferentes ambientes. 2008. 116p. Tese (Doutorado) - Universidade Federal de Viçosa, Viçosa.

HYTEN, D.L.; PANTALONE, V.R.; SAMS, C.E.; SAXTON, A.M.; LANDAUELLIS, D.; STEFANIAK, T.R.; SCHMIDT, M.E. Seed quality QTL in a prominent soybean population. Theoretical and Applied Genetics, v.109, p.552-561, 2004. DOI: 10.1007/ s0012200416615.

LEE, S.H.; BAILEY, M.A.; MIAN, M.A.R.; SHIPE, E.R.; ASHLEY, D.A.; PARROT, W.A.; HUSSEY, R.S.; BOERMA, H.R. Identification of quantitative trait loci for plant height, lodging, and maturity in a soybean population segregating for growth habit. Theoretical and Applied Genetics, v.92, p.516-523, 1996. DOI: 10.1007/BF00224553.

LI, W.; SUN, D.; DU, Y.; CHEN, Q.; ZHANG, Z.; QIU, L.; SUN, G. Quantitative trait loci underlying the development of seed composition in soybean (Glycine max L. Merr.). Genome, v.50, p.1067-1077, 2007. DOI: 10.1139/G07080.

MARQUEZ, M.C. Adaptabilidade, estabilidade e diversidade genética de cultivares de soja em três épocas de semeadura em Uberlândia - MG. 2010. 84p. Tese (Mestrado) - Universidade Federal de Viçosa, Viçosa, MG, Brasil.

NICHOLS, D.M.; GLOVER, K.D.; CARLSON, S.R.; SPECHT, J.E.; DIERS, B.W. Fine mapping of a seed protein QTL on soybean linkage group I and its correlated effects on agronomic traits. Crop Science, v.46, p.834-839, 2006. DOI: 10.2135/cropsci2005.050168.

ORF, J.H.; CHASE, K.; JARVIK, T.; MANSUR, L.M.; CREGAN, P.B.; ADLER, F.R.; LARK, K.G. Genetics of soybean agronomic traits: I. comparison of three related recombinant inbred populations. Crop Science, v.39, p.1642-1651, 1999. DOI: 10.2135/cropsci1999.3961642x.

PANTHEE, D.R.; PANTALONE, V.R.; WEST, D.R.; SAXTON, A.M.; SAMS, C.E. Quantitative trait loci for seed protein and oil concentration and seed size in soybean. Crop Science, v.45, p.2015-2022, 2005. DOI: 10.2135/cropsci2004.0720.

PIOVESAN, N.D. Análises biométricas e moleculares visando o desenvolvimento de linhagens de soja com alto teor protéico e produtivas. 2008. 130p. Tese (Doutorado) - Universidade Federal de Viçosa, Viçosa.

REINPRECHT, Y.; POYSA, V.W.; YU, K.; RAJCAN, I.; ABLETT, G.R.; PAULS, K.P. Seed and agronomic QTL in low linolenic acid, lipoxygenasefree soybean (Glycine $\max (\mathrm{L}$.) Merrill) germplasm. Genome, v.49, p.1510-1527, 2006. DOI: 10.1139/g06-112.

RODRIGUES, J.I. da S.; MIRANDA, F.D. de; FERREIRA, A.; BORGES, L.L.; FERREIRA, M.F. da S.; GOODGOD, P.I.V.; PIOVESAN, N.D.; BARROS, E.G. de; CRUZ, C.D.; MOREIRA, M.A. Mapeamento de QTL para conteúdos de proteína e óleo em 
soja. Pesquisa Agropecuária Brasileira, v.45, p.472-480, 2010. DOI: $10.1590 / \mathrm{S} 0100204 \mathrm{X} 2010000500006$.

SEBOLT, A.M.; SHOEMAKER, R.C.; DIERS, B.W. Analysis of a quantitative trait locus allele from wild soybean that increases seed protein. Crop Science, v.40, p.1438-1444, 2000. DOI: 10.2135/ cropsci2000.4051438x.

SHI, A.; CHEN, P.; ZHANG, B.; HOU, A. Genetic diversity and association analysis of protein and oil content in foodgrade soybeans from Asia and the United States. Plant Breeding, v.129, p. 250-256, 2010. DOI: 10.1111/j.14390523.2010.01766.x.

SHIBATA, M.; TAKAYAMA, K.; UJIIE, A.; YAMADA, T.; ABE, J.; KITAMURA, K. Genetic relationship between lipid content and linolenic acid concentration in soybean seeds. Breeding Science, v.58, p.361-366, 2008. DOI: 10.1270/jsbbs.58.361.

SOARES, T.C.B.; GOODGOD, P.I.V.; MIRANDA, F.D. de; SOARES, Y.J.B.; SCHUSTER, I.; PIOVESAN, N.D.; BARROS, E.G.; MOREIRA, M.A. QTL mapping for protein content in soybean cultivated in two tropical environments. Pesquisa Agropecuária Brasileira, v.43, p.1533-1541, 2008. DOI: 10.1590/ S0100204X2008001100012.

SPECHT, J.E.; CHASE, K.; MACRANDER, M.; GRAEF, B.L.; CHUNG, J.; MARKWELL, J.P.; GERMANN, M.; ORF, J.H.; LARK, K.G. Soybean response to water: a QTL analysis of drought tolerance. Crop Science, v.41, p.493-509, 2001. DOI: 10.2135/ cropsci2001.412493x.

TAJUDDIN, T.; WATANABE, S.; YAMANAKA, N.; HARADA, $\mathrm{K}$. Analysis of quantitative trait loci for protein and lipid contents in soybean seeds using recombinant inbred lines. Breeding Science, v.53, p.133-140, 2003. DOI: 10.1270/jsbbs.53.133.

ZHANG, W.K.; WANG, Y.J.; LUO, G.Z.; ZHANG, J.S.; HE, C.Y.; WU, X.L.; GAI, J.Y.; CHEN, S.Y. QTL mapping of ten agronomic traits on the soybean (Glycine max L. Merr.) genetic map and their association with EST markers. Theoretical and Applied Genetics, v.108, p.1131-1139, 2004. DOI: 10.1007/s00122-003-1527-2.

Recebido em 25 de junho de 2012 e aprovado em 28 de fevereiro de 2013 